\title{
Dried Residues of Specific Cruciferous Plants Incorporated into Soil can Suppress the Growth of Ralstonia solanacearum, Independently of Glucosinolate Content of the Residues
}

\author{
ANDRIANTSOA RANARISON OLIVIER ${ }^{1 *}$, YASUSHI UdA ${ }^{1}$, SANG WOO BANG ${ }^{1}$, HitOSHI HONJO ${ }^{1}$, \\ MOTOHIRO FUKAMI ${ }^{1}$ and RYO FUKUI ${ }^{1}$ \\ ${ }^{1}$ Faculty of Agriculture, Utsunomiya University, Minemachi 350, Utsunomiya, Tochigi 325-8505, Japan
}

(Received October 5, 2005-Accepted December 27, 2005)

The growth and survival of a rifampicin-resistant strain (22R6) of Ralstonia solanacearum were monitored after incorporation of cruciferous plants into infested soil. Air-dried residues of eighteen cruciferous plants (including two amphidiploid lines) were individually added to soil at a rate of $1.6 \%(\mathrm{w} / \mathrm{w})$ and the water condition maintained at $-10 \mathrm{kPa}$. Within one month of incubation at $24^{\circ} \mathrm{C}$, nine of the 18 residues reduced the population of the strain 22R6; B. rapa sp. rapifera 'Ayumi', Brassica oxyrrhina, and an amphidiploid line of Brassicoraphanus, were most inhibitory. In contrast, total soil bacteria increased, regardless of the nature of the residue. After infested soil was incorporated with cruciferous plant residues and pre-incubated for one month in glasshouse, wilt-susceptible tomato were transplanted and monitored for 34-days on residue-treated soil. The pathogen was detected in shoots of only $2-7 \%$ of tomato grown respectively in soil with residue of $B$. rapa sp. rapifera 'Ayumi' and Diplotaxis muralis against $47 \%$ of tomato in non-residue soil. Data indicated that suppressive effects of the residues might depend on nutritional status and undefined factor in the soil but were not directly dependent on the concentration of glucosinolates $\left(7.2 \times 10^{-3}-1.1 \times 10^{1} \mu \mathrm{mole}^{-1}\right.$ tissue $)$ in the residues and in vitro tests showed that authentic isothiocyanates were inhibitory to the pathogen only at high concentrations (more than $2 \mu$ mole $\mathrm{g}^{-1}$ soil).

Key words: cruciferous plants, glucosinolates (isothiocyanates), suppressive soil

Residues or extracts of cruciferous plants have been investigated by researchers for their effects on soil-borne disease control ${ }^{14,17,21,24)}$. Cruciferous plants are known to contain glucosinolates, i.e., sulfur-containing secondary metabolites, which are hydrolyzed to produce isothiocyanates (ITCs). ITCs exhibit inhibitory effects on a wide variety of microbes ${ }^{1,20)}$. Brown et al. ${ }^{3)}$ demonstrated the toxic effects of degradation products of glucosinolates from $B$. napus seed meal on Aphanomyces euteiches f. sp. pisi. Koike et al. ${ }^{14)}$ found that broccoli residue incorporated into soil reduced the incidence of Verticillium wilt in cauliflower. Glucosinolates and their breakdown compounds were found to inhibit soil-nitrifying bacteria ${ }^{1)}$. Inhibitory

\footnotetext{
* Corresponding author; E-mail: andriantsoar@yahoo.com, Tel \& Fax: +81-28-656-6826
}

effects on plant pathogens following the incorporation of cruciferous plant residues into soil have been attributed to the "biofumigation"13) by the toxic volatile compounds released from the degradation of glucosinolates ${ }^{2)}$. However, following soil incorporation of cruciferous plant residues, "biofumigation" by the degradation products of glucosinolates may not be the only active mechanism responsible for the inhibition of soil microorganisms. The suppression of apple-rot pathogens following the incorporation of cruciferous plant residues into soil was independent of the glucosinolate content of the plants ${ }^{19)}$.

The amendment of soil with organic matter increases soil biomass and can enhance the activity of specific antagonists within the community of soil microorganisms ${ }^{7,12)}$. Incorporation of plant residues may be effective for establishing and sustaining soil conditions that can suppress soil-borne 
diseases. The impacts of residues of cruciferous plants on disease such as bacterial wilt need to be studied in relation to the mode of inhibition of soil microbes in general. In this experiment, air-dried residues were used and could be handled easily and may, therefore, be practical in culture. Investigation was extended to wild species that are generally considered non-beneficial plants or weeds, which may possess potent or previously unidentified anti-pathogenic properties.

This study examined the effects of air-dried residues of various cultivated and wild cruciferous plants on strain 22R6. The survival and growth of the population of the strain 22R6 in treated soil was first monitored and afterwards tomato plant invasion and colonization by strain 22R6 was evaluated when wilt-susceptible tomato seedlings were transplanted in residue-treated soil. The study was focused on determination of an eventual correlation between the glucosinolate content of air-dried residues and their effect on survival of the strain 22R6 in soil and the colonization of tomato plant host.

\section{Materials and Methods}

\section{Soil}

The test was carried out, by using soil samples, which has been managed differently for more than ten years, in fertilization. The soil samples were taken (at a depth of 0-20 cm) from plots of a paddy field of the experimental farm of Utsunomiya University. The first soil (AoM soil) has been fertilized repeatedly with farmyard manure $\left.{ }^{17}\right)\left(20 \mathrm{t} \mathrm{ha}^{-1}\right.$. year $^{-1}$ ) since 1992 . The $\mathrm{pH}$ of AoM soil was 5.18. The second soil $\left(\mathrm{B}_{2}\right)$ has been continuously fertilized with chemical fertilizer $\left(50 \mathrm{~kg} \mathrm{~N} \mathrm{ha}^{-1}\right.$. year ${ }^{-1}$ in 1991, and $100 \mathrm{~kg} \mathrm{~N} \mathrm{ha}^{-1}$. year $^{-1}$ in 1992 and thereafter). The $\mathrm{pH}$ of $\mathrm{B}_{2}$ soil was 4.65 . The soil samples were sieved through 8.6-mesh (pore size: 2

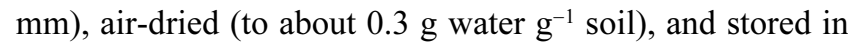
room temperature until use.

\section{Cruciferous plants and preparation of plant residues}

The plants used in this study are listed in Table 1. The

Table 1. Cruciferous plants tested in this study

\begin{tabular}{|c|c|c|c|c|}
\hline Scientific name & Common name & Genome type & Chromosome number & Cultivar number \\
\hline Brassica oleracia'Ajihaba'a & Cabbage & $\mathrm{CC}$ & $2 \mathrm{n}=18$ & 03951 \\
\hline B. oleracia 'Taasai' ${ }^{\text {a }}$ & Chinese mustard & $\mathrm{CC}$ & $2 \mathrm{n}=18$ & 01886 \\
\hline B. rapa sp. pekinensis 'Kyoshu'a & Chinese cabbage & AA & $2 n=20$ & 07521 \\
\hline B. rapa sp. rapifera 'Aoi'a & Green mustard & AA & $2 n=20$ & 04888 \\
\hline B. rapa sp. rapifera 'Ayumi' ${ }^{a}$ & Green mustard & AA & $2 n=20$ & \\
\hline B. fructilosa Cyr. $^{\text {b }}$ & & FF FF & $2 n=32$ & - \\
\hline B. oxyrrhina Coss. ${ }^{\mathrm{b}}$ & & $\mathrm{OO}$ & $2 \mathrm{n}=18$ & - \\
\hline Sinapsis alba L. ${ }^{\mathrm{b}}$ & & Sal Sal & $2 n=24$ & - \\
\hline S. arvensis L. ${ }^{\mathrm{b}}$ & & Sar Sar & $2 n=18$ & \\
\hline S. turgita (pers.) L. ${ }^{\text {b }}$ & & Stu Stu & $2 \mathrm{n}=18$ & - \\
\hline Eruca sativa Lam. ${ }^{\mathrm{b}}$ & & Esa Esa & $2 n=22$ & - \\
\hline E. vesicaria (L.) DC. ${ }^{\mathrm{b}}$ & & Eve Eve & $2 n=22$ & - \\
\hline Diplotaxis erucoides (L.) DC. ${ }^{b}$ & & Der Der & $2 n=14$ & - \\
\hline D. muralis (L.) DC. ${ }^{\mathrm{b}}$ & & Dmu Dmu & $2 n=42$ & - \\
\hline Moricandia arvensis (L.) $\mathrm{DC}^{\mathrm{b}}$ & & Mar Mar & $2 n=28$ & - \\
\hline Orychophragmus violaceus (L.) O. E. Schulz ${ }^{\mathrm{c}}$ & & Ov Ov & $2 n=24$ & - \\
\hline Brassicoraphanus $^{\mathrm{d}}$ & & OORR & $2 n=36$ & - \\
\hline Raphanobrassica & & RRCC & $2 n=36$ & - \\
\hline
\end{tabular}

a Seeds originally from the Tohoku Seed Company

${ }^{\mathrm{b}}$ Seeds originally from Tohoku University

c Plants grew indigenously on the campus of Utsunomiya University

${ }^{\mathrm{d}}$ Amphidiploid line of B. oxyrrhina X Raphanus sativus

e Amphidiploid line of Raphanus sativus X B. oleracia ssp. acephala

d, e (Seeds were obtained from Laboratory of Plant Breeding Utsunomiya University) 
seeds were sown in a commercial soil mix (Sakata Seed Corporation, Yokohama) for 3-4 weeks and were transplanted to an on-campus field plot. The plot was fertilized with an inorganic fertilizer at a rate of 36,65 , and $57 \mathrm{~kg}$ $\mathrm{ha}^{-1}$ of $\mathrm{N}, \mathrm{P}_{2} \mathrm{O}_{5}, \mathrm{~K}_{2} \mathrm{O}$, respectively, prior to planting. Three months after transplanting, terrestrial parts of the plants were harvested, cut into pieces $(\leq 10 \mathrm{~mm})$, and air-dried in the laboratory. The air-dried plant residues were then ground with a mixer and sieved through a 16-mesh (pore size: $1 \mathrm{~mm}$ ) and were stored in a desiccator until use. The residue of Trifolium pratense (L.) 'Harukaze' (clover) was prepared with the same manner in the Laboratory of Plant Pathology at Osaka Prefectural University, Osaka Japan.

\section{Bacterial strain}

Strain MAFF301522 (race 1, biovar 3) of $R$. solanacearum was obtained from the Gene Bank of the Ministry of Agriculture, Forestry, and Fisheries of Japan. The 22R6 strain used in this study was a spontaneous mutant resistant to rifampicin and was chosen for this test because of its highest pathogenicity on tomato plants as compared to the other wild strains during preliminary test (data not shown). Bacterial cells were grown on $\mathrm{BGT}^{16)}$ agar medium without 2,3,5-triphenyl-2H-tetrazolium chloride (TZC), suspended in sterile-distilled water and the turbidity of the inoculum cell suspension was adjusted to 0.1 of $\mathrm{O}^{\mathrm{D}_{600}}$ (approximately $2 \times 10^{8} \mathrm{CFU} \mathrm{ml}^{-1}$ ).

Growth and survival of the strain 22R6 in soils amended with different cruciferous plant residues

Microcosm (300-ml plastic cup, four replicates) was prepared by pouring approximately $100 \mathrm{~g}$ of soil, which was mixed thoroughly with the air-dried residue of each plant species at a rate of $1.6 \%(\mathrm{w} / \mathrm{w})$. The $22 \mathrm{R} 6$ strain was inoculated into soil to obtain approximately $10^{7} \mathrm{CFU} \mathrm{g}^{-1}$ soil, which was adjusted to water potential corresponding to -10 $\mathrm{kPa}$. Before its incubation at $24^{\circ} \mathrm{C}$, each cup was covered with a lid having five holes (5-mm diameter). The holes were covered with oxygen-permeable $\left(260 \mathrm{ml} \mathrm{m}^{-2} \mathrm{hr}^{-1}\right.$ at 1 atm, $30^{\circ} \mathrm{C}$ ) parafilm (Novix-II, Asahi Techno Glass, Tokyo) to avoid strict anaerobic condition. To measure the soil population of 22R6 strain, $5 \mathrm{~g}$ of soil sample was suspended in $45 \mathrm{ml}$ of $10 \mathrm{mM}$ phosphate buffer ( $\mathrm{pH} \mathrm{6.9)}$ and shaken (75 tours $\mathrm{min}^{-1}$ ) for $30 \mathrm{~min}$ in a $200-\mathrm{ml}$ flask. Serial dilutions $\left(10^{-6} \sim 10^{-2}\right)$ of soil suspension were prepared and plated on BGT containing $50 \mu \mathrm{g} \mathrm{ml}^{-1}$ of rifampicin and $100 \mu \mathrm{g} \mathrm{ml}^{-1}$ of cycloheximide (Sigma, St Louis, MO). The same dilutions were also plated on 1/10-strength Triptic Soy Agar containing $100 \mu \mathrm{g} \mathrm{ml}^{-1}$ of cycloheximide, to determine the popula- tion of culturable "total" bacteria. Effect of each residue on strain 22R6 was examined at least once in three separate experiments, each including B. rapa sp. rapifera 'Aoi' and $O$. violaceus for comparison.

The effects of the residues, which suppressed strain 22R6 in AoM soil were tested in the second $\mathrm{B}_{2}$ soil, with the same method as in the previous test. Residue of 'Harukaze' was included and used as a non-cruciferous plant control.

\section{Colonization of tomato seedlings by strain $22 R 6$ and its survival in residue-treated soil}

The residues of $D$. muralis and $B$. rapa sp. rapifera 'Ayumi', because of their suppressive effect on strain 22R6 in soil and their relatively higher glucosinolate content, were chosen among wild and cultivated species for the bioassay. AoM soil was previously inoculated with strain 22R6 $\left(10^{7} \mathrm{CFU} \mathrm{g}^{-1}\right.$ soil $)$ and incorporated with each residue, at a rate of $1.6 \%(\mathrm{w} / \mathrm{w})$ and pre-incubated for 30-days. The colonization of tomato plants by strain 22R6 was evaluated by monitoring wilt-susceptible tomato ('Lycopersicon esculentum Mill cv 'Momotarou') that was grown in residuetreated soil. The survival of strain 22R6 in treated soil was measured before tomato transplantation (after 2 and 4weeks incubation) and after upper part of tomato hosts have been removed.

The pre-incubation of residues-incorporated soils was performed with uncovered plastic container (15-L) in glasshouse before its transfer into new seedling containers $(6 \times 5 \times 5 \mathrm{~cm} 4 \times 4$ wells) for the bioassay test. The soil was moistened two times a day, to maintain the water content approximately to $-10 \mathrm{kPa}$. Seeds of tomato were previously sown on AoM soil in other containers, having $3 \times 2.5 \times 2.5 \mathrm{~cm}$ $6 \times 6$ wells, to prepare 96 seedlings per treatment. Eight days old tomato seedlings, with the soil in each well, were transplanted into the pre-treated AoM soil of the bioassay, with meticulous care to avoid root damage. The temperature in the glasshouse has been automatically recorded during the experiment. The bioassay test has been set for 34-days but tomato seedling showing a typical wilting symptom was removed and examined in advance. Tomato shoots were cut at upper $(6 \mathrm{~cm}$ above the soil) at middle positions $(3 \mathrm{~cm}$ above the soil) and at lower positions $(0.5 \mathrm{~cm}$ above the soil) of the stems. The cut ends of the stems were inoculated onto BGT agar plates containing $50 \mu \mathrm{g} \mathrm{ml}^{-1}$ of rifampicin as described previously to verify the presence of the bacteria in tomato shoots. The media were incubated at $28^{\circ} \mathrm{C}$ for 2 days and the population of the strain 22R6 in AoM soils was measured by the dilution plate method described in the previous test. The presence of the pathogen in upper part of the 
shoot was considered to correspond to higher level of colonization of tomato seedling by strain 22R6. The level of infection of the tomato plants was determined as the portion of tomato seedlings infected by pathogen to the upper and lower positions of their stems. Infections up to the upper part of the stem were considered as higher severity of the disease.

\section{Quantitative and qualitative analysis of glucosinolates}

Glucosinolates were extracted with $70 \%$ methanol and converted to their derivative ITCs with previously prepared myrosinase $^{1)}$. The amounts of ITCs were determined by HPLC (JASCO LG-2080-02) at $365 \mathrm{~nm}$ using a column YMC Pack (150×4.6 mm) (JASCO Co., Ltd. Tokyo Japan). The eluting solvent was methanol/milli-Q water $(70 / 30$ by volume) and the flow rate was $0.75 \mathrm{ml} \mathrm{min}^{-1}$. Standard solutions were prepared with synthesized 2-phenylethyl ITC.

For qualitative analysis extracts, prepared with $50 \mathrm{~g}$ of $B$. oxyrrhina and $O$. violaceus plant were suspended in ethylether $(100 \mathrm{ml})$ and dehydrated with $2 \mathrm{~g}$ of $\mathrm{Na}_{2} \mathrm{SO}_{4}$. After being concentrated on a vacuum rotary-evaporator to about $5 \mathrm{ml}$ of concentrate, the concentrates were analyzed by GC (Hewlett Packard 5890 series II) coupled with a mass spectrometer (Hewlett Packard 5971 1A), using a column HP 5 (0.25 mm $\times 30 \mathrm{~m}$; Hewlett Packard) (Compco Analytical, Inc. NJ USA).

In vitro inhibitory test on strain 22R6 of two synthesized ITCs on culture media and in soil

Benzyl-ITC reportedly has a stronger inhibitory effect on bacteria than phenyl-ITC or phenylethyl-ITC ${ }^{20)}$. Inhibitory effects of benzyl-ITC (Aldrich Chem. Co. Milwaukee, WI) and 2-phenylethyl-ITC (Kanto Chem. Co.), the main types of ITCs found in the residues of B. oxyrrhina and $O$. violaceus, on strain 22R6 were tested. In preliminary experiments the two ITCs did not inhibit growth of the strain 22R6 at concentrations below $1 \mathrm{mM}$. The two ITCs were dissolved in acetone to prepare ITC solutions at concentrations ranging from $100 \mu \mathrm{M}$ to $100 \mathrm{mM}$. A $10-\mathrm{mm}$ diameter sterilized filter paper disc (1.1 mm thick) was placed on a sterile cupric-made support, which was installed in the center of the lid of a $90 \times 15-\mathrm{mm}$ Petri dish. Fifty micro-litre of each prepared ITC solution were poured onto the filter paper. Hundred micro-litre of pathogen cell suspensions, containing about $10^{5} \mathrm{CFU} \mathrm{ml}^{-1}$, were inoculated respectively on BGT, a nutrient-rich medium and on 1/100strength Nutrient Agar (1/100 NA), a low-nutrient medium, to evaluate the inhibitory effects of ITCs on strain 22R6, growing in a high- or low-nutrient environment. The cell suspensions were inoculated on agar medium (three replicates) in the bottom dish, which then was placed onto the lid in an inverse position. The dishes were sealed with regular parafilm and incubated at $24^{\circ} \mathrm{C}$. Plates receiving only acetone and sterile-distilled water were included as controls. Two days after inoculation, the filter papers were removed and the colonies formed on agar plates were counted. Two days after the first counting, the colonies of the strain 22R6 on plates were enumerated again to re-evaluate its growth, without it being exposed to ITC.

The same test was performed with AoM soil. Five gram of AoM soil inoculated with the strain 22R6 (10 $\mathrm{CFU} \mathrm{g}^{-1}$ soil) was installed in the center of one compartment of the lid of a partitioned Petri dish $(90 \times 15 \mathrm{~mm})$. ITC solutions ranging from $100 \mu \mathrm{M}$ to $100 \mathrm{mM}$ were prepared with acetone, as it was described in previous test. Two sterilized filter paper discs (10-mm diameter, $1.1 \mathrm{~mm}$ thick) were placed on a sterile cupric-made support, which was installed in the center of the half compartment of the lid of partitioned $90 \times 15-\mathrm{mm}$ Petri dish. Hundred micro-litre of each prepared ITC solution were poured onto the filter papers and the dishes were sealed with regular parafilm. Plates receiving only acetone and sterile-distilled water were included as controls. After two days incubation at $24^{\circ} \mathrm{C}$, the filter papers were removed and the colonies of the strain 22R6 remaining in soil were counted by dilution plating method with BGT media.

Effect of soil enrichment with nutrients on the growth of the strain 22R6 in soil with or without plant residues

The growth and survival of the strain 22R6 in soil enriched with glucose or peptone were monitored after 0,1 , 3 , and 7 days of inoculation of the strain 22R6 (about $10^{5}$ $\mathrm{CFU} \mathrm{g}^{-1}$ soil). The nutrient-enriched soil was amended with air-dried residues of B. oxyrrhina and Brassicoraphanus. Glucose and peptone solutions were poured and mixed with the inoculated soil and their concentrations were adjusted to approximately $2.3 \mathrm{mg} \mathrm{g}^{-1}$ soil. No residues were mixed into non-treated soil. Residue-incorporated soil that was not inoculated with bacteria was also prepared as a control. The water potential of each prepared soil was set to $-10 \mathrm{kPa}$. The culturable populations of the strain 22R6 and "total" bacteria were determined by dilution plating method. The same experiment was also carried out to test the residues of B. rapa sp. rapifera 'Ayumi', and Brassicoraphanus by inoculating into AoM soil, cell suspension containing $10^{7}$ $\mathrm{CFU} \mathrm{g}^{-1}$ soil. 


\section{Statistical analysis}

The log-transformed data for bacterial populations were first analyzed by analysis of variance (ANOVA), and the means were separated in pair-wise comparisons by a protected Fisher's Least Significant Difference (LSD) test. In the ANOVA, sampling day was considered the repeatedmeasures factor.

\section{Results}

Growth and survival of the strain 22R6 in soils amended with air-dried residues of different cruciferous plants

Among 18 different cruciferous plants tested, residues of nine plants, of which seven were non-cultivated species, suppressed the strain 22R6, at least once, in AoM soil by four weeks of treatment. In all experiments, culturable population of the strain 22R6 in non-treated soil remained stable or declined only slightly over four weeks of incubation. Serial dilutions from non-inoculated soils were inoculated on BGT with rifampicin, but bacterial colonies did not appear on the media plate, even at the highest $\left(\times 10^{-2}\right)$ concentration of serial dilutions.

In the first series of experiment, testing residues of eighteen cruciferous plants in AoM soil, the residues of B. rapa sp. rapifera 'Ayumi', B. oxyrrhina, Brassicoraphanus, B. fructilosa Cyr., Dyplotaxis muralis (L.) DC., Sinapsis arvensis L. and Moricandia arvensis significantly reduced the population of the strain 22R6 after 30-days of incubation (Table 2). The residue of Sinapsis turgita T (pers.) L. and Raphanobrassica also reduced the population of the strain 22R6 after 30-days of incubation but the test could not be reproduced two times (not shown in the table). The residues of Eruca sativa; B. rapa sp. pekinensis 'Kyoshu'; B. oleracia 'Ajihaba'; E. vesicaria; S. alba; D. erucoides, the residues of $B$. oleracia 'Taasai', and B. rapa sp. rapifera 'Aoi' (not shown in the table) did not significantly reduce the population of the strain $22 \mathrm{R} 6$, as compared to the nontreated soil. Similarly, the population of the strain 22R6, in the AoM soil incorporated with the residues of $O$. violaceus, which were included in each test as control, did not significantly differ from that in non-treated soil after 30-days incubation. In all experiments, the total bacterial count in the soil increased significantly within 30-days, regardless of the plants and their effects on strain 22R6 (Table 2).

In the second experiment, the residues of cruciferous plants that had been suppressive in the previous experiments were selected and repeatedly incorporated into soil. The survival of the strain 22R6 was re-examined and the residue of clover was used as a non-cruciferous control. Decrease of the population of the strain 22R6 was again evident in soils amended with residues of $B$. rapa sp. rapifera 'Ayumi', B. oxyrrhina, D. muralis, and the amphidiploid line of Brassicoraphanus, four weeks after inoculation (Table 2). However, the residues of S. arvensis, B. fructilosa, and $M$. arvensis did not significantly decrease the population of the strain 22R6 in this second test. The total bacterial counts increased significantly regardless of the species or cultivars of the residues. The residue of Trifolium pratense 'Harukaze', which were included in each test as

Table 2. Effect of the addition of cruciferous plant residues on the fate of the strain 22R6 and total culturable bacteria in AoM soil

\begin{tabular}{|c|c|c|c|c|}
\hline \multirow{3}{*}{ Residues of } & \multicolumn{4}{|c|}{$\log _{\mathrm{CFU}} \mathrm{g}^{-1}$ dry AoM soil } \\
\hline & \multicolumn{2}{|c|}{ Experiment 1} & \multicolumn{2}{|c|}{ Experiment 2} \\
\hline & Strain 22R6 & Total bacteria & Strain 22R6 & Total bacteria \\
\hline Control & 6.45 & 6.49 & 6.45 & 6.41 \\
\hline B. rapa sp. rapifera 'Ayumi' & $3.74 *$ & $6.97 *$ & $5.34 *$ & $7.13^{*}$ \\
\hline B. oxyrrhina Coss. & $3.94 *$ & $6.97 *$ & $5.08^{*}$ & $7.30 *$ \\
\hline Brassicoraphanus & $4.73^{*}$ & $7.17^{*}$ & $5.55^{*}$ & $7.35^{*}$ \\
\hline B. fructilosa Cyr. & $5.05 *$ & $7.09 *$ & 5.99 & $7.23 *$ \\
\hline D. muralis (L.) DC. & $5.14 *$ & $7.02 *$ & $5.38^{*}$ & $7.16^{*}$ \\
\hline S. arvensis L. & $5.23 *$ & $7.11^{*}$ & 5.94 & $7.27^{*}$ \\
\hline Moricandia arvensis (L.) DC & $5.40^{*}$ & $7.10^{*}$ & 6.43 & $7.31 *$ \\
\hline Orychophragmus violaceus (L.) & 6.05 & $7.14 *$ & 6.26 & $7.27 *$ \\
\hline Trifolium pratense 'Harukaze' & 6.27 & $7.15 *$ & 6.53 & $7.32 *$ \\
\hline
\end{tabular}

Data of 30 days after inoculation are shown

* Means indicated by asterisks are significantly different $(\mathrm{P}=0.05)$ from the corresponding control mean accordingly to a protected LSD test. 
Table 3. Effect of the addition of cruciferous plant residues on the fate of the strain 22R6 and total culturable bacteria in $B_{2}$ soil

\begin{tabular}{lcc}
\hline \multirow{2}{*}{ Residues of } & \multicolumn{2}{c}{ Log CFU g ${ }^{-1}$ dry $\mathrm{B}_{2}$ soil } \\
\cline { 2 - 3 } & Strain 22R6 & Total bacteria \\
\hline Control & 6.70 & 6.92 \\
B. rapa sp. rapifera 'Ayumi' & $5.73^{*}$ & $7.50^{*}$ \\
B. oxyrrhina Coss. & $5.29^{*}$ & $7.31^{*}$ \\
B. fructilosa Cyr. & $5.87^{*}$ & $7.30^{*}$ \\
Brassicoraphanus & $6.07^{*}$ & $7.54^{*}$ \\
Orychophragmus violaceus (L.) & 6.58 & $7.50^{*}$ \\
Trifolium pratense 'Harukaze' & $6.20^{*}$ & $7.57^{*}$ \\
\hline
\end{tabular}

Data of 30 days after inoculation are shown

* Means indicated by asterisks are significantly different $(\mathrm{P}=0.05)$ from the corresponding control mean accordingly to a protected LSD test.

control, did not decrease significantly the population of the strain 22R6 in AoM soil (Table 2).

In the second soil, $\mathrm{B}_{2}$, the population of the strain 22R6 was reduced progressively, over four weeks, in soil amended with the residues of B. rapa sp. rapifera 'Ayumi', B. oxyrrhina, Brassicoraphanus and B. fructilosa, (Table 3). As was observed in AoM soil, the population of the strain 22R6 did not change significantly in soil containing the residue of $O$. violaceus but in soil incorporated with the residue of Trifolium pratense 'Harukaze' the population of the strain 22R6 decreased as compared to control. Total bacterial counts increased in response to the incorporation of residue into the soil (Table 3).

Colonization of tomato seedlings by strain 22R6 and its survival in residue-treated soil

In non-residue soil, strain 22R6 was detected in higher parts of the stem of $47 \%$ of tomatoes plants after 34-days of treatment. In soil treated with the residues of D. muralis, strain 22R6 was present in higher parts of the stems of 7\% of seedling and was present in $2 \%$ of the plants for the soil mixed with B. rapa sp. rapifera 'Ayumi' (Fig. 1) and the number of wilted tomato was respectively 2, 7 against 52 in non-residue soil. Before tomato transplantation, the population of the strain 22R6 was $6.40\left(\log\right.$ CFU g ${ }^{-1}$ dry soil) in soil without residue while it corresponded to 4.64 and 5.12 respectively in the soil incorporated with the residues of $B$. rapa sp. rapifera 'Ayumi' and D. muralis (Fig. 2).

The population of the strain 22R6 in soil continued to decline in residue-incorporated soils while tomato hosts were growing for 34-days. After all the shoots of seedlings

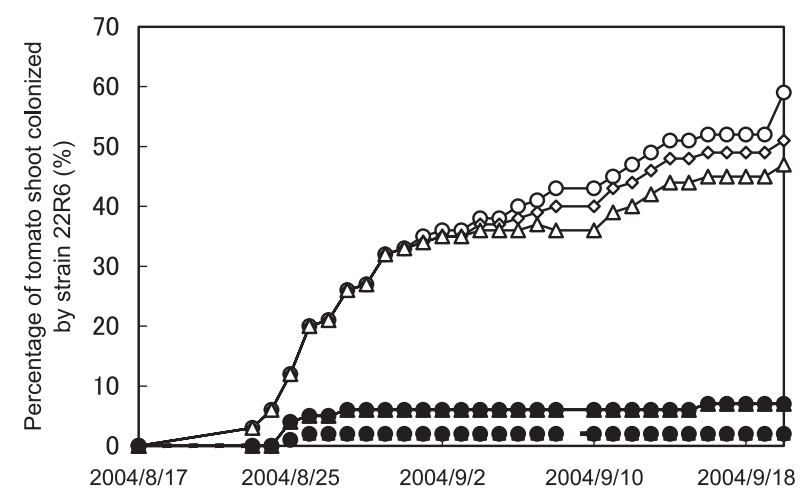

Fig. 1. Percentage of tomato shoot colonized by strain 22R6 in lower, medium and higher parts of the stems of tomato seedlings grown in soil without residue $(\mathrm{K})$, in soil incorporated with the residue of D. muralis (Dmu) and B. rapa sp. rapifera 'Ayumi' ('Ayumi').
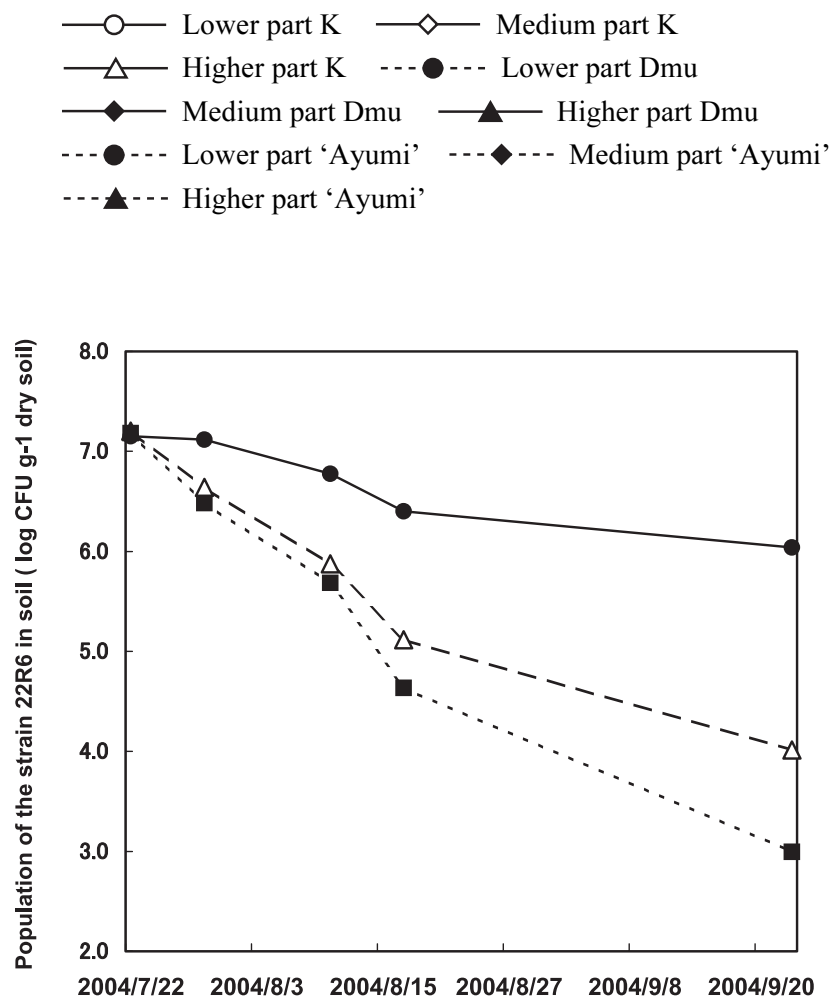

Fig. 2. Population of the strain $22 \mathrm{R} 6$ in the soil incorporated with residues of B. rapa sp. rapifera 'Ayumi' and D. muralis and in non-residue soil.

--- --- Non residue soil

............... Soil with the residue of B. rapa sp. rapifera 'Ayumi'

- - $\triangle$ - - Soil with the residue of $D$. muralis

The pre-incubation of the residue-incorporated soil, in glasshouse, was performed from 2004/7/17 to 2004/8/18.

The bioassay of tomato seedlings was performed from 2004/8/18 to $2004 / 9 / 22$ 
were cut and removed from the container, the population of the strain 22R6 were determined to be $6.24 ; 3.57$ and 2.45 ( $\log$ CFU $\mathrm{g}^{-1}$ dry soil) respectively in non-residue soil, in soil treated with the residue of $D$. muralis and in soil treated with the residue of B. rapa sp. rapifera 'Ayumi' (Fig. 2).

Total glucosinolate contents in plant residues and their relation to suppressive effects on strain $22 R 6$

The amount of total glucosinolates extracted from one gram of plant residue ranged from $7.2 \times 10^{-3} \mu$ mole $\mathrm{g}^{-1}$ for $T$. pratense to $1.1 \times 10^{1} \mu$ mole $\mathrm{g}^{-1}$ for $D$. erucoides (Table 4 ). No obvious correlations were evident between total glucosinolates content in residues and their suppressive effects on strain 22R6.

Qualitative analysis of ITCs in the residues of

B. oxyrrhina and $\mathrm{O}$. violaceus

Three major ITCs were identified in the fresh materials of each plant (B. oxyrrhima and $O$. violaceus), and 3-butenylITC and 4-methylthiobutyl-ITC were detected in both residues. Benzyl-ITC was detected only in the residue of $O$. violaceus, while 2-phenylethyl-ITC was detected only in the residue of $B$. oxyrrhina.

In vitro inhibitory test of benzyl-ITCs and 2-phenylethyl ITC on strain $22 R 6$

Benzyl-ITC and 2-phenylethyl-ITC exhibited clear inhibitory effects on strain 22R6 when $5 \mu$ mole of each ITC were
Table 4. Total glucosinolate content of residues of cruciferous and non-cruciferous plants

\begin{tabular}{lc}
\hline \multicolumn{1}{c}{ Plants } & $\begin{array}{c}\text { Glucosinolate content } \\
\left(\mu \text { mole } \mathrm{g}^{-1} \text { residue }\right)\end{array}$ \\
\hline Trifolium pratense 'Harukaze' & $7.2 \times 10^{-3}$ \\
B. oxyrrhina & $9.9 \times 10^{-2}$ \\
Raphanobrassica & $1.3 \times 10^{-1}$ \\
Brassicoraphanus & $3.2 \times 10^{-1}$ \\
O. violaceus & $5.4 \times 10^{-1}$ \\
M. arvensis & $1.4 \times 10^{0}$ \\
B. fructilosa & $2.0 \times 10^{0}$ \\
B. rapa sp. rapifera 'Ayumi' & $2.2 \times 10^{0}$ \\
S. arvensis & $3.0 \times 10^{0}$ \\
S. turgita & $3.4 \times 10^{0}$ \\
B. rapa sp. rapifera 'Aoi' & $4.0 \times 10^{0}$ \\
E. sativa & $7.1 \times 10^{0}$ \\
D. muralis & $9.9 \times 10^{0}$ \\
D. erucoides & $1.1 \times 10^{1}$ \\
\hline
\end{tabular}

loaded onto the sterilized filter paper disc (using $100 \mathrm{mM}$ of solutions; Table 5). After two days of exposure to these ITC solutions at $100 \mathrm{mM}$, no colonies were observed on the agar plates of BGT and 1/100 NA under a light microscope. Benzyl-ITC also reduced the number of colonies on BGT at a concentration of $10 \mathrm{mM}(0.5 \mu \mathrm{mole})$. At lower concentrations, the numbers of colonies on both media were not sig-

Table 5. Effects of benzyl-ITC and 2-phenylethyl-ITC on the growth of the strain 22R6 on culture media

\begin{tabular}{|c|c|c|c|c|c|}
\hline \multirow{3}{*}{ Incubation } & \multirow{3}{*}{ Concentration } & \multicolumn{4}{|c|}{ Number of bacterial colony counted on culture media } \\
\hline & & \multicolumn{2}{|c|}{ Benzyl-ITC } & \multicolumn{2}{|c|}{ 2-Phenylethyl-ITC } \\
\hline & & On BGT & On NA/100 & On BGT & On NA/100 \\
\hline \multirow[t]{6}{*}{ After 2 days exposure } & Distilled water & 115.3 & 112.7 & 115.3 & 112.7 \\
\hline & Acetone & 108.0 & 122.7 & 108.0 & 122.7 \\
\hline & $100 \mu \mathrm{M}$ & 109.3 & 114.7 & 122.7 & 124.0 \\
\hline & $1 \mathrm{mM}$ & 98.0 & 104.0 & 116.7 & 110.0 \\
\hline & $10 \mathrm{mM}$ & $63.3^{*}$ & 98.0 & 90.0 & 108.0 \\
\hline & $100 \mathrm{mM}$ & $0^{*}$ & $0^{*}$ & $0^{*}$ & $0^{*}$ \\
\hline \multirow[t]{6}{*}{ After 2 days exposure plus 2 days non-exposure } & Distilled water & 115.3 & 112.7 & 115.3 & 112.7 \\
\hline & Acetone & 108.0 & 122.7 & 108.0 & 122.7 \\
\hline & $100 \mu \mathrm{M}$ & 109.3 & 114.7 & 122.7 & 124.0 \\
\hline & $1 \mathrm{mM}$ & 98.0 & 104.0 & 116.7 & 110.0 \\
\hline & $10 \mathrm{mM}$ & $63.3^{*}$ & 98.0 & 90.0 & 108.0 \\
\hline & $100 \mathrm{mM}$ & $0 *$ & $0^{*}$ & $83.3^{*}$ & 107.3 \\
\hline
\end{tabular}

Means indicated by asterisks $(*)$ are significantly different $(\mathrm{P}=0.05)$ from the corresponding control means (distilled water) according to a protected Fisher's LSD test. 
Table 6. Effects of benzyl-ITC and 2-phenylethyl-ITC on the growth of the strain 22R6 in AoM soil

\begin{tabular}{llcc}
\hline & & Log CFU g ${ }^{-1}$ air-dried soil & \\
\cline { 2 - 4 } After 2 days of incubation & Concentration & benzyl-ITC & 2-phenyl-ethyl-ITC \\
\hline & Distilled water & 5.31 & 5.31 \\
& Acetone & 5.35 & 5.35 \\
& $100 \mathrm{mM}$ & $4.58^{*}$ & 5.28 \\
& $10 \mathrm{mM}$ & 5.32 & 5.33 \\
& $1 \mathrm{mM}$ & 5.31 & 5.44 \\
After 7 days of incubation & $100 \mu \mathrm{M}$ & 5.31 & 5.35 \\
& $10 \mu \mathrm{M}$ & 5.33 & 5.26 \\
& Distilled water & 5.14 & 5.14 \\
& Acetone & 5.13 & 5.13 \\
& $100 \mathrm{mM}$ & $4.43 *$ & 5.25 \\
& $10 \mathrm{mM}$ & 5.16 & 5.36 \\
\end{tabular}

Means indicated by asterisks $(*)$ are significantly different $(\mathrm{P}=0.05)$ from the corresponding control means (distilled water) according to a protected Fisher's LSD test.

nificantly different from the numbers counted on control plates. When the filter papers containing the ITC solutions were removed from the agar plates, that were further incubated for an additional two days, colonies of the strain 22R6 appeared on the plates that had been exposed to $100 \mathrm{mM}$ of 2-phenylethyl-ITC, but the number of colonies on BGT was significantly lower than that on the control plates. In contrast, strain 22R6 did not grow on plates that had been exposed to $100 \mathrm{mM}$ of benzyl-ITC, even after the chemical was removed.

Furthermore the population of the strain 22R6, in tested AoM soil, decreased significantly, as compared to the control, after two and seven days of exposure to $10 \mu$ mole of benzyl-ITC (100 mM of ITC solutions, Table 6). The population of the strain 22R6 in soil did not significantly change when exposed to 2-phenylethyl ITC.

Effect of soil enrichment with nutrients on the growth of the strain 22R6 in soil with or without plant residues

In response to the addition of either glucose or peptone to AoM soil, the culturable populations of the strain 22R6 increased within one day, and the elevated CFU of these populations was maintained over the next six days (Table 7). Addition of the same nutrient sources into soil containing residues of B. oxyrrhina and Brassicoraphanus, however, did not increase the population of the strain 22R6. On the contrary in the soil enriched with glucose, the popula- tion of the strain 22R6 in soil containing residues of B. oxyrrhina was lower than in soil without nutrient, after seven days of incubation (Table 7). A similar result was obtained in a previous test when the residue of $B$. rapa sp. rapifera 'Ayumi' was incorporated into the soil (data not shown). The population of total bacteria increased significantly in response to the incorporation of both residues into the soil (data not shown).

\section{Discussion}

The results showed that Lower concentration of the pathogen in soil resulted in lower colonization of the tomato plant host. Reduction of the soil population of the strain 22R 6 could be obtained by incorporation of residue of specific cruciferous plant, which contained different glucosinolate content.

The residues of $B$. oxyrrhina, $B$. rapa $\mathrm{sp}$. rapifera 'Ayumi', and the amphidiploid line of Brassicoraphanus exhibited consistently suppressive effects on strain 22R6, but their glucosinolate contents were relatively low $\left(9.9 \times 10^{-2}-2.2 \times 10^{0} \mu\right.$ mole $\left.\mathrm{g}^{-1}\right)$. The residue of $O$. violaceus, which had a low glucosinolate content, and B. rapa sp. rapifera 'Aoi', which had a relatively high glucosinolate content, did not decrease the population of the strain 22R6 within 30-days. Although the residues of E. sativa, D. erucoides, and D. muralis had a relatively high glucosinolate 
Table 7. Effects of soil enrichment with nutrients on the growth of the strain 22R6 in soil with or without plant residues ${ }^{\mathrm{a}}$

\begin{tabular}{|c|c|c|c|c|}
\hline \multirow[t]{2}{*}{ Incubation period (day) } & \multirow[t]{2}{*}{ Soil treatment (incorporated residue) } & \multicolumn{3}{|c|}{$\begin{array}{l}\text { Culturable population of the strain } 22 \mathrm{R} 6 \text { in soil } \\
\text { amended with nutrients }\left(\log \mathrm{CFU} \mathrm{g} \mathrm{g}^{-1} \text { soil }\right)^{\mathrm{b}}\end{array}$} \\
\hline & & Control & Glucose & Peptone \\
\hline \multirow{3}{*}{0} & Non-treated & $5.35 \mathrm{a}$ & $5.17 \mathrm{a}$ & $5.42 \mathrm{a}$ \\
\hline & B. oxyrrhina Coss & $5.27 \mathrm{a}$ & $5.28 \mathrm{a}$ & $5.42 \mathrm{a}$ \\
\hline & Brassicoraphanus & $5.30 \mathrm{a}$ & $5.17 \mathrm{a}$ & $5.19 \mathrm{a}$ \\
\hline \multirow{3}{*}{1} & Non-treated & $5.39 \mathrm{a}$ & $6.68 \mathrm{~b}$ & $7.01 \mathrm{c}$ \\
\hline & B. oxyrrhina Coss & $5.56 \mathrm{a}$ & $5.28 \mathrm{a}$ & $5.42 \mathrm{a}$ \\
\hline & Brassicoraphanus & $5.54 \mathrm{a}$ & $5.28 \mathrm{a}$ & $5.37 \mathrm{a}$ \\
\hline \multirow{3}{*}{3} & Non-treated & $5.46 \mathrm{a}$ & $7.55 \mathrm{c}$ & $7.60 \mathrm{c}$ \\
\hline & B. oxyrrhina Coss & $5.96 \mathrm{~b}$ & $5.52 \mathrm{a}$ & $5.72 \mathrm{ab}$ \\
\hline & Brassicoraphanus & $5.89 \mathrm{~b}$ & $5.47 \mathrm{a}$ & $5.62 \mathrm{a}$ \\
\hline \multirow{3}{*}{7} & Non-treated & $5.52 \mathrm{c}$ & $7.02 \mathrm{~d}$ & $7.03 \mathrm{~d}$ \\
\hline & B. oxyrrhina Coss & $5.31 \mathrm{bc}$ & $4.95 \mathrm{a}$ & $5.30 \mathrm{bc}$ \\
\hline & Brassicoraphanus & $5.18 \mathrm{ab}$ & $4.95 \mathrm{a}$ & $5.39 \mathrm{bc}$ \\
\hline
\end{tabular}

\footnotetext{
a The concentration of nutrient solution used to moisten the soil was $2.3 \mathrm{mg} \mathrm{g}^{-1}$ soil to adjust the concentration of each substance in the soil water to $0.5 \%$.

${ }^{\mathrm{b}}$ The means for the same incubation period indicated by the same letters are not significantly different $(\mathrm{P}=0.05)$ according to a protected Fisher's LSD test.
}

content (respectively $7.1 \times 10^{0}$ and $9.9 \times 10^{0} \mu$ mole g $^{-1}$ ), only the residue of $D$. muralis significantly reduced the strain 22R6, and its suppressive effect on strain 22R6 was comparable to that of $S$. arvensis and B. fructilosa, which contained $2.0 \times 10^{0}-3.0 \times 10^{0} \mu$ mole $\mathrm{g}^{-1}$ of total glucosinolates. The pathogen was detected in shoot of $7 \%$ of tomato on $D$. muralis-residue treated soil while it was present in shoot of only $2 \%$ of tomato in soil incorporated with the residue of B. rapa sp. rapifera 'Ayumi' even if the residues of $D$. muralis, contained higher glucosinolate content $\left(9.9 \times 10^{0}\right.$ $\mu$ mole $\left.\mathrm{g}^{-1}\right)$ as compared to the residue of $B$. rapa sp. rapifera 'Ayumi' $\left(2.2 \times 10^{0} \mu\right.$ mole $\left.^{-1}\right)$. Furthermore, during bioassay, which was performed in uncovered containers in glasshouse, the cruciferous plant residue, reduced the population of the strain 22R6 to 3.57 in soil with the residue of $D$. muralis while it reduced to 2.45 in soil with residue of $B$. rapa sp. rapifera 'Ayumi', regardless of their glucosinolate content. Finally the residue of non-cruciferous 'Harukaze', which does not contain glucosinolate reduced the population of the strain 22R6 in $\mathrm{B}_{2}$ soil. In general, no correlation was established between the suppressive effects of the residues and their glucosinolate content found in the air-dried plants tested.

The result of the in vitro test showed that $5 \mu$ mole (per medium plate) and $2 \mu$ mole $\mathrm{g}^{-1}$ soil of synthesized ITC inhibited the strain 22R6 respectively on culture media and in soil (Tables 5 and 6). In this experiment, the soil incorporated with the residues of $B$. oxyrrhina contained approximately $1.6 \times 10^{-3} \mu$ mole $\mathrm{g}^{-1}$ soil of total glucosinolates. Even if all glucosinolates in the residues were transformed to ITCs, the resulting concentration of ITC would be below the level required to produce any inhibitory effect on strain 22R6. Furthermore, the population of the strain 22R6 in soil containing the residue of $O$. violaceus, which contained approximately $8.3 \times 10^{-3} \mu$ mole $\mathrm{g}^{-1}$ soil of glucosinolate, increased. This result Indicates that the bactericidal effect of benzyl-ITC, which was the main constituent of $O$. violaceus was not enough, at low concentration, to affect the survival of the strain 22R6 under the given soil conditions. Since glucosinolate contents in these residues were not sufficient to produce inhibitory effects, the growth of the strain 22R6 may have been suppressed by other mechanisms.

The growth of the pathogen was affected by the quality of the nutrient source added to the soil. Elsewhere Sofos and Samelis ${ }^{29)}$ reported that inhibitory effect of biocontrol agent Pseudomonas sp. against Escherichia coli was stimulated by the presence of free glucose. In soil incorporated with the residue of B. oxyrrhina the population of the strain 22R6 was significantly lower when glucose was added to soil as compared to that in non-enriched soil (Table 7). Tajul et $a l{ }^{30)}$ reported that higher bacterial wilt occurrence in farmyard manure fertilized soil, as compared to that in the bark 
compost-fertilized soil was due to the relatively higher amount of water soluble organic compound and lower $\mathrm{C} / \mathrm{N}$ ratio in farmyard manure-fertilized soil. But our results indicated that growth suppression of the pathogen might have been also affected by the nutrient source in soil. Difference of the available nutrient sources from degradation of each residue incorporated into soil might be one of the factors that can affect their effect toward strain 22R6.

Furthermore, most of the residues increased the total bacterial counts in the soils, indicating that the residues were used as a "food source" for soil bacteria. Decline of the strain 22R6 was always accompanied by an increase in total bacterial counts, growth suppression of this pathogen may have been linked to the activity of certain soil bacterial communities formed in response to soil amendment with plant residues or to a specific bacterial strain (or a group of strains) amplified by specific food sources.

\section{Acknowledgements}

We are thankful to Yukio Kaneko for his critical reading of the manuscript. Thanks are also extended to Koichi Yoneyama of the Weed Sciences Department, Utsunomiya University, for his advice on chemical analyses. We also thank Tojo Motoaki of the Laboratory of Plant Pathology at Osaka Prefectural University for providing the clover residue.

\section{References}

1) Bending, G.D. and D.L. Suzanne. 2000. Inhibition of soil nitrifying bacteria communities and their activities by glucosinolate hydrolysis products. Soil Biol. Biochem. 32: 1261-1269.

2) Brown, P.D. and M.J. Morra. 1999. Control of soil borne plant pests using glucosinolate-containing plants. Adv. Agron. 61: 167-231.

3) Brown, P.D., U. Smolinska, M.J. Morra and G.R. Knudsen. 1996. Toxicity of glucosinolate degradation products from Brassica napus seed meal toward Aphanomyces euteiches f. sp. pisi. Phytopatology 87: 77-82.

4) Bruehl, G.W. 1987. Survival of bacteria in soil. p. 184-195. In Soilborne plant pathogens. Macmillan Co. N.Y.

5) Dick, W.A. and I.A. Al-Turki. 2003. Myrosinase activity in soil. Soil Sci. Soc. Am. J. 67: 139-145.

6) Duncan, A.J. 1991. Toxic substances in crop plants. D'Mello, J.P.F., C.M. Duffus and J.H. Duffus. The Royal Society of Chemistry: Cambridge. 126-147.

7) Fukui, R. 2003. Suppression of soilborne plant pathogens through community evolution of soil microorganisms. Microbes Environ. 18: $1-9$.

8) Fukui, R., G.S. Campbell and R.J. Cook. 1994. Factors influencing the incidence of embryo infection by Pythium sp. during germination of wheat seeds in soils. Phytopathology 84: 695-702.
9) Gamliel, A. and J.J. Stapleton. 1993. Characterization of antifungal volatile compounds evolved from solarized soil amended with cabbage residues. Phytopathology 83: 899-905.

10) Girlanda, M., S. Perotto, Y. Moenne-Loccos, R. Bergero, A. Lazzari, G. Defago, P. Bonfante and A.M. Luppi. 2001. Impact of biocontrol agent Pseudomonas fluorescens CHAO and a genetically modified derivative on the diversity of culturable fungi in the cucumber rhizosphere. Appl. Environ. Microbiol. 67: 18511864.

11) Grey, B.E. and T.R. Steck. 2001. The viable but non-culturable state of Ralstonia solanacearum may be involved in long-term survival and plant infection. Appl. Environ. Microbiol. 67: 38663872.

12) Hoitink, H.A.J. and M. Boehm. 1999. Biocontrol within the context of soil microbial communities: A substrate-dependent phenomenon. Annu. Rev. Phytopathol. 37: 427-446.

13) Kirkegaard, J., P.T.W. Wong, J.M. Desmarchelier and J.F. Angus. 1993. Biofumigation-Using Brassica species to control pests and diseases in horticulture and agriculture. p. 77-82. In Wratten, N. and R. Mailer (ed.), Proceedings of the $9^{\text {th }}$ Australian Research Assembly on Brassica. Wagga. NSW Agriculture.

14) Koike, S.T. and K. Subbarao. 2000. Broccoli residues can control Verticillium wilt of cauliflower. California Agriculture 54: 3033.

15) MacGibbon, D.B. and R.M. Allison. 1970. A method for the separation and detection of plant glucosinolases (myrosinases). Phytochemistry 9: 541-544.

16) McDouglas, D., S. Rice, D. Weichart and S. Jelleberg. 1998. Nonculturability: adaptation or debilitation? FEMS Microbiol. Ecol. 25: 1-9.

17) Maeda, T. and H. Hirai. 2002. Effects of continuous application of farmyard manure on the physico-chemical characteristics of the soil and root system, nutrient absorption, and yield of rice cultured with minimal agricultural chemicals. Jpn. J. Crop Sci. 71: 506-512. (In Japanese).

18) Manning, W.J. and D.F. Crossan. 1969. Field and greenhouse studies on the effects of plant amendments on Rhizoctonia hypocotyl rot of snapbean. Plant Dis. Rep. 53: 227-231.

19) Mazzola, M., D.M. Granatstein, D.C. Elfving and K. Mullinix. 2001. Suppression of specific apple rot pathogen by Brassica napus seed meal amendment regardless of glucosinolate content. Phytopathology 91: 673-679.

20) McKay, A.F.D., L. Garmaise, R. Gaudry, H.A. Baker, G.Y. Paris, R.W. Kay, G.E. Just and R. Schartz. 1959. The chemical and bacteriostatic properties of isothiocyanates and their derivatives. J. Amer. Chem. Soc. 81: 4328-4335.

21) Morra, M.J., P.D. Brown, J.P. McCaffrey, L.A. Dick and L. Williams. 1991. Allelochemicals produced during glucosinolate degradation in soil. J. Chem. Ecol. 17: 2021-2034.

22) Muehlchen, A.M., R.E. and J.L. Parke. 1990. Evaluation of crucifer green manure for controlling Aphanomyces root rot of peas. Plant Dis. 74: 651-654.

23) Palmieri, S., L.M. Manici and 1. Lazzeri. 1997. In vitro fungitoxic activity of some glucosinolates and their enzyme-derived products toward plant pathogenic fungi. J. Agric. Food Chem. 45: 2768-2773.

24) Ramirez, V. and D.E. Munnecke. 1988. Effect of solar heating and soil amendment of cruciferous residues on Fusarium oxysporum f. sp. conglutinans and other organisms. Phytopathology 78: $289-295$. 
25) Rosa, E. and P. Rodrigues. 1999. Towards a more sustainable agriculture system: The effect of glucosinolates on the control of soil borne diseases. J. Hortic. Sci. Biotech. 74: 667-674.

26) Saile, E., J.A. McGarvey, M.A. Schell and T.P. Denny. 1997. Role of extracellular polysaccharide and endoglucanase in root invasion and colonization of tomato plants by $R$. solanacearum. Phytopathology 87: 1264-1271.

27) Scott, J.S. and G.R. Knudsen. 1999. Soil amendment effects of rape (Brassica napus) residues on pea rhizosphere bacteria. Soil Biol. Biochem. 31: 1435-1441.

28) Shiomi, Y., M. Nishiyama, T. Onizuka and T. Marumoto. 1999. Comparison of bacterial community structures in the rhizoplane of tomato plants grown in soils suppressive and conducive towards bacterial wilt. Appl. Environ. Microbiol. 65: 3996-4001.

29) Sofos J.N. and J. Samelis. 2002. Role of Glucose in Enhancing the Temperature-Dependent Growth Inhibition of Escherichia coli O157:H7 ATCC 43895 by a Pseudomonas sp. Appl. Environ. Microbiol. 68: 2600-2604.
30) Tajul, M.D. Islam and K. Toyota. 2004. Suppression of bacterial wilt of tomato by Ralstonia solanacearum by incorporation of composts in soil and possible mechanisms. Microbes. Environ. 19: 53-60.

31) Talalay, P., Y. Zhang, C. Cho and G.H. Posner. 1992. Spectroscopic quantitation of organic isothiocyanate by cyclocondensation with vicinal dithiols. Anal. Biochem. 205: 100-107.

32) Tsuchiya, K. 2003. Biocontrol and environmental risks. In Tsuchiya, K. and S. Tsushima, (ed.). Biological control of plant disease and soil management. Proc. p. 1-10. $8^{\text {th }}$ PSJ Biocontrol workshop. The Phytopathological Society of Japan, Tokyo.

33) Vincent, V.M. and T.W. Mew. 1998. Effect of soil amendment on the survival of Ralstonia solanacearum in different soils. Phytopathology 88: 300-305.

34) Walker, G.E. and B.G. Morey. 1999. Effect of brassica and weed manures on abundance of Tylenchulus semipenetrans and fungi in citrus orchard soil. Aust. J. Exp. Agric. 39: 65-72. 